\title{
Assessment of the Effect of Pharmacotherapy in Common Cold/Acute Bronchitis - the Bronchitis Severity Scale (BSS)
}

\author{
Beurteilung der Wirksamkeit von Pharmakotherapie bei \\ Erkältungen/akuter Bronchitis: Bronchitis Severity Scale (BSS)
}

Authors

Institutions
P. Kardos' ${ }^{1}$ S. Lehrl'², W. Kamin ${ }^{3}$, H. Matthys ${ }^{4}$

${ }^{1}$ Group Practice and Centre for Pneumology, Allergy and Sleep Medicine at Red Cross Maingau Hospital, Frankfurt am Main ${ }^{2}$ Department of Psychiatry and Psychotherapy, Friedrich-Alexander University Erlangen-Nuremberg, Erlangen

${ }^{3}$ Pediatric Clinic, Evangelic Hospital Hamm GmbH, Hamm

${ }^{4}$ Medical Director emeritus, Department of Pneumology, University Hospital Freiburg received 10.4 .2014 accepted after revision 30.4.2014

\section{Bibliography}

Dol http://dx.doi.org/

10.1055/s-0034-1377332

Published online: 8.7.2014

Pneumologie 2014; 68: 542-546

(c) Georg Thieme Verlag KG

Stuttgart · New York

ISSN 0934-8387

Corresponding author

Dr. med. Peter Kardos

Scheffelstr. 33

60318 Frankfurt

info@Lungenpraxis-Maingau.de

\section{Abstract \\ $\nabla$}

Background: Acute bronchitis (AB) is a highly contagious infection of the airways, presenting mostly in connection with common cold (CC). There is a high variance in duration and course of symptoms which, sooner or later, also may disappear spontaneously and change during the course of the disease. Therefore, assessment of treatment outcome is difficult.

Methods: Composite outcome measures are commonly used to examine the effects of pharmacotherapy in complex diseases. We discuss the features of the Bronchitis Severity Scale (BSS) on the basis of the available literature.

Results: For the BSS the five most important symptoms of $A B$ are rated by the patient and the physician. Since its introduction in 1996, the BSS has been used in many clinical trials evaluating treatment effects of $A B$. Its score correlates well with clinical findings. As thorough validation analyses revealed, this applies even more to the BSS subscales "cough domain" and "sputum domain".

Conclusion: The validated BSS appears to be a reliable tool to assess therapeutic effects in CC/AB. The BSS and its subscales are recommended as outcome measures for future drug trials in $\mathrm{CC} /$ $A B$, but also help physicians to focus their consultation in patients with $\mathrm{CC} / \mathrm{AB}$.

\section{Introduction}

Common cold (CC) is a viral infection of the upper airways also referred to as upper respiratory tract infection (URI) and including acute rhinosinusitis, pharyngitis and laryngitis. URI usually appears jointly with acute bronchitis (AB) and differentiation is almost unfeasible [1]. Cough, wheezing and sometimes sputum production are the leading symptoms of $\mathrm{AB}$, but considerable overlap ex-

\section{Zusammenfassung \\ $\nabla$}

Hintergrund: Akute Bronchitis $(\mathrm{AB})$ ist eine Entzündung der Atemwege. Sie tritt meist im Rahmen eines Erkältungsinfektes auf (engl. common cold; (C). Die klinische Symptomatik ist in Dauer und Verlauf äußerst variabel, früher oder später spontan abklingend und kann sich im Krankheitsverlauf ändern, was die Beurteilung der Wirksamkeit von Therapiemaßnahmen erschwert.

Methode: Zur Einschätzung von Behandlungsmaßnahmen bei komplexen Krankheiten werden oft zusammengesetzte Ratingskalen eingesetzt. Wir stellen die Bronchitis Severity Scale (BSS) vor und diskutieren sie anhand vorhandener Literatur.

Ergebnisse: Für die BSS werden die 5 wichtigsten Symptome bei AB von Patient und Arzt eingeschätzt. Seit ihrer Einführung 1996 wurde die BSS in vielen klinischen Studien zur Einschätzung von Therapieeffekten bei AB genutzt. Ihre Resultate stimmten stets gut mit der klinischen Situation überein. Die Validierungsanalyse zeigte, dass die BSS-Unterskalen „Hustendomäne“ und „Sputumdomäne“ die klinischen Gegebenheiten noch genauer widerspiegeln.

Schlussfolgerungen: Die validierte BSS und ihre Unterskalen eignen sich zur Einschätzung von Therapieeffekten bei CC/AB. Sie werden als Zielparameter für klinische Studien empfohlen und erleichtern auch Ärzten die Diagnose.

ists between these two conditions where symptoms are related to different areas of the upper and lower airways [1].

$\mathrm{CC} / \mathrm{AB}$ leads to approximately 75 to 100 million physician visits annually only in the U.S.[2]. CC and other acute respiratory infections account for about $30 \%$ of absenteeism from school and approximately $40 \%$ of time lost from work, including parents staying home to care for their sick children and millions of employees suffering 
from a cold [3]. CC/AB affects about $5 \%$ of adults annually [4] and is one of the most common outpatient illnesses recorded by physicians; in the UK, 30 to $40 \%$ of registered patients consult their physicians for treatment of respiratory tract infections each year [5]. Thus, although they are usually self-limiting, these clinical conditions pose a very large financial burden for societies and a great symptom burden for patients.

Although the great majority of cases of $\mathrm{CC} / \mathrm{AB}$ relates to viruses (mainly rhinovirus (50\% of cases), influenza A and B viruses, parainfluenza virus, RSV, coronavirus, adenovirus) and only up to $10 \%$ of cases are caused by bacteria (mainly Mycoplasma pneumoniae, Chlamydia pneumoniae, Bordetella pertussis), antibiotics are the most common prescribed treatment worldwide $[4,6]$. But superiority of appropriate antibiotic treatment in otherwise healthy patients could not be shown even in cases of bacterial infection $[4,7,8]$. According to recent Cochrane reviews, antibiotics should not be prescribed in uncomplicated $\mathrm{AB}[8]$ and rhinosinusitis [9]; for persistent cough, evidence even in children is insufficient and recommendations for antibiotic treatment cannot be given [10]. Overall, the small beneficial effect of antibiotic treatment in meta-analysis should be considered in the context of potential adverse events, the cost of antibiotics and, most important, of increasing antibiotic resistances. Furthermore, the usual over-the-counter (OTC) treatment with mucolytic and antitussive agents shows no evidence for or against their efficacy, i.e. is not supported by data from clinical trials [4].

\section{Assessment of pharmacotherapy}

Proof of efficacy in contemporary pharmacotherapy is based on randomized controlled trials (RCTs). Designing RCTs in CC/AB is especially demanding, since it is a complex, self-limiting disease. There is a large variance in symptoms in CC, where patients suffer from sore throat, rhinorrhea, nasal stuffiness, headache, cough, sputum production, chest pain, and wheeze. All symptoms are highly variable, i.e. they may change spontaneously during the course of the disease and in some cases decrease rapidly. For example, using the Leicester Cough Monitor, an objective and valid tool to assess cough frequency $[11,12]$, Lee et al. found more than $50 \%$ cough reduction after the first 24 hours in patients with acute cough receiving no treatment [13]. Thus, high placebo effects must be taken into account when symptomatic treatment options are evaluated. On the other hand, cough is the most bothersome and long-lasting symptom in CC [14], with a mean resolution time as long as 25 days.

To examine the effects of pharmacotherapy in complex diseases, composite assessment scores are commonly used. Rheumatologists employ different composite measures to assess rheumatoid arthritis [15], psychiatrists commonly rate depression in clinical research by multiple item questionnaires such as the Hamilton Depression Rating Scale (HDRS) [16] or the Montgomery-Asberg Depression Rating Scale (MADRS) [17], and physicians treating athletes experienced concussion have been relying on the SCAT2-score (Sport Concussion Assessment Tool) for years [18]. Potential benefits of composite outcome scales are their ability to measure clinically relevant changes even in cases where not all of the single endpoints of interest changed or where the endpoints changed to a different extent. Patient-reported outcome instruments are also valuable for evaluating symptom improvements and are used in different areas of respiratory medicine
[19], e.g. chronic obstructive pulmonary disease (COPD), asthma research, pulmonary arterial hypertension (PAH), etc.

The need for a reliable instrument to estimate disease severity in $A B$ is supported by the efforts of Mwachari and colleagues who employed a multiple item instrument called the Acute Bronchitis Severity Score (ABSS) in 2007 [20,21]. Patients rate the degree of five items (overall severity of health, day cough, night cough, limited daily activity, and fever) bothering them within the past 24 hours. However, "fever" is rather unusual in $\mathrm{CC} / \mathrm{AB}$ and apart from the very initial phase it cannot be considered as an appropriate item to rate the severity. Therefore, its use as a score item should be seen rather critically. The main disadvantage of this patient-rated questionnaire is that the ABSS is only validated in a high human immunodeficiency virus (HIV) prevalence setting fpr patients aged 18 years or older [20]. It was adopted in only one clinical trial in Africa [21].

\section{The Bronchitis Severity Scale (BSS) \\ $\nabla$}

Concerning AB sensu stricto, Dome et al. filled the gap of an appropriate outcome measure by introducing the Bronchitis Severity Scale (BSS) in 1996 [22]. The scale comprises the five most important features of $A B$, i.e. cough, sputum production (expectoration), rales/rhonchi (auscultation), chest pain during coughing, and dyspnoea [23]. The BSS is an instrument which combines objective and subjective items, because the assessment is based on the investigator's clinical evaluation in conjunction with the subjective feedback of the patient. Each constituent of the BSS is assessed by the investigator using a 5-point verbal rating scale ranging from 0 to 4 (0: absent; 1 : mild; 2 : moderate; 3 : severe; 4: very severe). The total score of BSS is the sum of the five ratings with a maximum of 20 points.

Since its introduction in 1996 [22], the BSS has been successfully used in many clinical studies as a main outcome measure in patients suffering from $\mathrm{AB}$. Most of these research groups evaluated the efficacy of a herbal drug preparation (EPs 7630 ${ }^{1}$ ) extracted from the roots of Pelargonium sidoides [24-34]. EPs 7630 has been approved for the treatment of $A B$ in Germany and is used in several other countries as an alternative therapy option for ear, nose, throat, and respiratory tract infections [28]. Other studies employed the BSS to evaluate other treatment options in $A B$, e.g. extracts of ivy leaves [35], combinations of thyme and primrose extracts [36-38], distillates of eucalyptus oil extract and lemon peel extract [39], and thyme/ivy combinations [40,41]. The generalization of the BSS as an endpoint in the different studies shows that the score has become an established tool for consistent evaluation of $\mathrm{AB}$ symptoms which could change independently from each other and across patients [23-41].

\section{A recent example for the use of BSS - a composite scale $\nabla$}

Matthys et al. [31] reported the results of a randomised, doubleblind, placebo-controlled study investigating the efficacy and tolerability of EPs 7630 tablets by means of the BSS. A total of 406 adults with $\mathrm{AB}$ were randomly assigned to one of four treat-

\footnotetext{
${ }^{1} \mathrm{EPs}^{\circledR} 7630$ is the active ingredient of the product Umckaloabo ${ }^{\circledR}$ (ISO Arzneimittel, Ettlingen, Germany).
} 
ment groups (three different doses of EPs 7630 and one placebo) and treated for seven days. Primary outcome measure was the change of the BSS between baseline and day 7. As expected in a self-limiting disease, BSS decreased in all groups but showed a significant greater reduction in the groups treated with EPs 7630 ( $\mathrm{p}<0.0001)$. This result was in line with the other patient reported outcomes, i.e. the IMOS (Integrative Medicine Outcome Scale) and the IMPSS (Integrative Medicine Patient Satisfaction Scale). IMOS and IMPSS are 5-point verbal rating scales, with IMOS describing the general health status of the patient (rated independently by both the investigator and the patients) and IMPSS rated by the patients and mirroring their satisfaction with treatment. Both scales have been used in several clinical studies assessing treatment outcome of $A B$ [22,24-26,31-34] and the European Committee for Homeopathy takes them into account for data collection, too [42]. Overall, the BSS total score, the IMPSS and the IMOS are in line with patient reported outcomes [31] as has been shown in earlier trials $[28,33]$.

\section{Validation of the BSS \\ $\nabla$}

Every composite endpoint has to fulfill validity criteria to be applied as a suitable outcome measure. In case of the BSS, validity has been analysed by Lehrl resulting in a comprehensive report [43]. The essence of this report is submitted for publication elsewhere. Here we give a short overview of the validation of the BSS. In total, 7 published randomized, double-blind controlled trials with EPs 7630 for which a complete data set was on file were used to validate the BSS as an outcome measure. For this, 2,033 patients (full analysis set) with $A B$ were included [24-26,28, $31-33]$. The BSS is designed to assess the treatment success of $A B$. When analysing the scale different aspects of validity were implied according to the classical test theory: (1) content validity, (2) construct validity and (3) criterion validity, with the latter being subdivided into (3a) concurrent validity and ( $3 b)$ predictive (prognostic) validity [44].

(1) For content validity of the BSS it is necessary that the symptoms included in the scale reflect the expert knowledge about AB. A further prerequisite, especially for valid application, is that all users of the scale, including family physicians, responsible for the treatment of the vast majority of patients with $\mathrm{CC} / \mathrm{AB}$, are able to rate the symptoms correctly. In conclusion, high content validity was reported for the BSS.

For (2) construct validity, generation of the scale has to be checked, i.e. it is crucial to find out if the instrument is in agreement with its underlying theory. Looking at the BSS, the five bronchitis-specific items must reflect the whole spectrum of the impact on health of patients suffering from $A B$. To ensure this univariate nature of $A B$, factor analyses (data from 7 studies [24-26,28, 31-33]) were performed resulting in two groups of factors which varied independently from each other ( $\bullet$ Fig. 1 ). The first factor, named "cough domain", includes the four symptoms cough, rales, chest pain and dyspnoea. The second factor only comprises the factor "sputum domain" and is named accordingly. Both factors proved to be independent i.e. a certain score (degree of severity) of the "cough domain" does not imply a corresponding severity score of the "sputum domain". Hence, the two factors can be designated as autonomous.

The main question for (3) criterion validity is if the scale really measures the parameters it is supposed to measure. Concerning the BSS, it should reflect the degree of severity of AB. Several

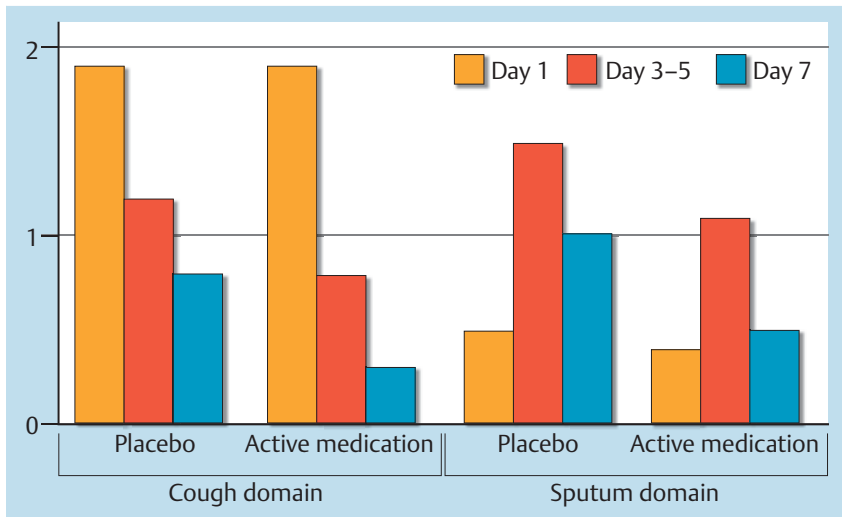

Fig. 1 The subscales "cough domain" and "sputum domain" (for the $y$-axis: courses of medians for severity) may result in different scores during the course of the disease (data from Chuchalin et al. [33]).

Table 1 Relationship between BSS score and severity of acute bronchitis [43].

\begin{tabular}{|l|l|}
\hline BSS total score & Clinical interpretation \\
\hline 0 & No acute bronchitis \\
\hline 1 to 2 & Acute bronchitis unlikely \\
\hline 3 to 7 & Mild acute bronchitis \\
\hline 8 to 12 & Moderate acute bronchitis \\
\hline 13 to 17 & Severe acute bronchitis \\
\hline 18 to 20 & Very severe acute bronchitis \\
\hline
\end{tabular}

criteria are involved, some of them concerning concurrent, other predictive validity. ( $3 a$ ) Concurrent validity was confirmed by means of statistical tests, i.e. the self-assessments by the patient of the 3 symptoms "cough", "sputum production" and "chest pain" were in line with the investigators assessments of the same symptoms [43]. Because of the combination of objective and subjective items that constitute the BSS, the assessment of the general practitioner can be done only in conjunction with the subjective feedback of the patient.

For $(3 b)$ predictive validity of the BSS, two prerequisites have to be fulfilled: 1) Even without medication, the BSS decreases in the week following the first visit. 2) Through treatment with an effective preparation, e.g. EPs 7630 in a double-blind, randomized, placebo-controlled trial, the BSS decreases more rapidly than through placebo treatment. According to the available studies [24-26,28,31-33], both predictions apply for the BSS and thus, the BSS meets the requirements of $(3 a)$ concurrent validity and $(3 b)$ predictive validity.

Finally, generalisation of the BSS can be stated, since assessment with the BSS appears to be largely independent of any special training for the assessing doctors, of their nationality, native language, age, or sex. This is also true for the patients being assessed: according to the analyses of Lehrl there is no indication for any systematic effect of patients' nationality, age, and sex on the outcome of the BSS [43]. Thus, the BSS can be recommended as a valid measurement tool for the severity of $A B$ ( Table 1$)$ and its validity has been recently accepted by the European Medicines Agency's (EMA) Committee on Herbal Medicinal Products (HMPC) [45]. 


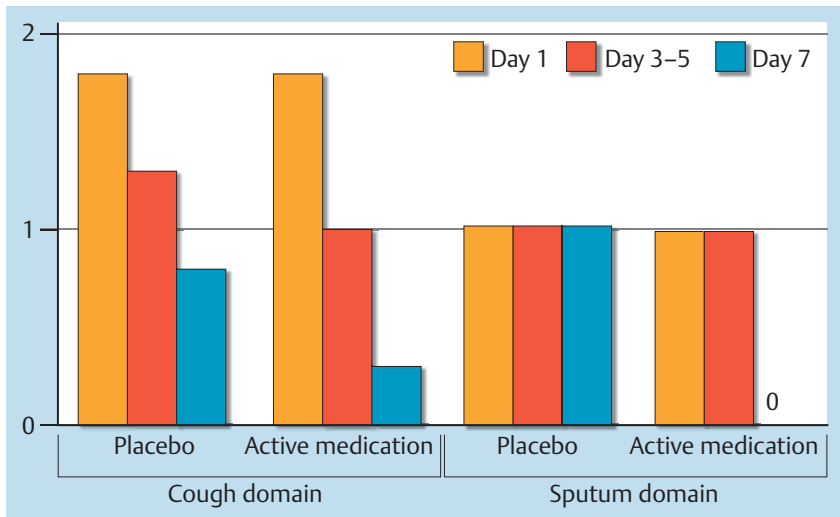

Fig. 2 Independent trend of the two domain scores (for the y-axis: courses of medians for severity) when all 1,955 patients of the seven studies are included (active drug: $n=1,181$; placebo: $n=774$ ) [43].

Table 2 Relationship between the score of the two BSS subscales and severity of acute bronchitis [43].

\begin{tabular}{|lll|}
\hline Score of BSS subscales & \multicolumn{2}{l|}{ Clinical interpretation } \\
\hline 0 & No acute bronchitis \\
\hline- & Cough & Sputum \\
\hline$>0$ and $<1.5$ & Mild & Mild \\
\hline 1.5 to 2.4 & Moderate & Moderate \\
\hline 2.5 to 3.4 & Severe & Severe \\
\hline 3.5 to 4.0 & Very severe & Very severe \\
\hline
\end{tabular}

\section{Limitations of the BSS}

\section{$\nabla$}

One major result of the validity check-up was the differentiation of the above mentioned subscales "cough domain" and "sputum domain" [43]. As shown in $\bullet$ Fig. 1 and $\bullet$ Fig. 2, sputum production may stay the same or even increase during the first days of the disease whereas the symptoms combined in the "cough domain" decrease constantly. However, this is in line with clinical reality: in everyday routine patients usually report an important relief, if after 2 - 3 days the cough becomes wet for a few days.

Furthermore, it was shown that EPs 7630 is very effective for cough relief when compared with placebo [25,26,31]. If once sputum production starts, coughing is no more a complaint for the patient and expectoration subsides rapidly (sputum score $=0$ at day 7 ( Fig. 2); i.e. no more phlegm will be coughed up, which is consistent with the clinical impression).

Thus, both complexes alone appear to reflect reality even better than the BSS total score and we recommend using these subscales to assess disease severity in $\mathrm{AB}$. To receive values similar to the ones shown in Table 2, the four variables of the "cough domain" must be summed up and the total divided by four, because they are interrelated. Clinical interpretation of the results according to $\bullet$ Table 2 and $\bullet$ Fig. 2 is then possible.

Both a weakness and strength of the BSS could be its subjective, patient reported character. However, in a self-limiting disease patient related outcomes are the most important ones and no other patient related outcomes for $C C / A B$ are available.

Overall, we consider the BSS as appropriate for the assessment of treatment response in $\mathrm{AB}$. Validation is based on well-designed and placebo-controlled trials and the results have been published in peer-reviewed journals. Nevertheless, we emphasize the need for further suitable studies employing the BSS with treatment options other than EPs 7630, which was used in most of the trials analysed here. Also, future trials should iterate even more on relating the BSS to clinically relevant changes of disease severity.

\section{Beyond randomized controlled trials}

Recently Matthys and Kamin reviewed all studies employing the BSS until April 2012 [46]. The authors state that improvement in the BSS found in these studies correlates with clinical outcomes and patients' satisfaction with treatment. Thus, they recommend further use of the BSS as a reliable and convenient clinical trial tool for selecting and evaluating patients in studies of $\mathrm{AB}$. But does the validated BSS help in clinical practice, too? Both for research and clinicians the evidence based BSS helps to determine which are clinically important symptoms in CC/AB. These ones should be assessed in individual patients. They help if the course of the disease is unusual, protracted and/or the decision on further diagnosis and treatment are pending [23]. Thus, the validated BSS, and especially its subscales, are recommended tools helping the doctor to focus the consultation and better manage patients with $C C / A B$, whatever is the prescribed therapy.

In conclusion, a validated BSS assessing pharmacotherapeutic effects in $C C / A B$ is now available. Using the subscales "cough domain" and "sputum domain" separately is considered to be even more helpful. They are useful and important tools for future drug trials in $C C / A B$, but they also help physicians to focus their consultation in many patients with $\mathrm{CC} / \mathrm{AB}{ }^{2}$

\section{Conflict of interest \\ $\nabla$}

All authors served on advisory board of Dr. Willmar Schwabe GmbH\&CoKG, Karlsruhe, Germany and received honoraria. Peter Kardos also received lecture and advisory board honoraria from Bionorica SE, 92318 Neumarkt, Germany.

\section{References}

1 Hueston WJ, Mainous AG3rd, Dacus EN et al. Does acute bronchitis really exist? A reconceptualization of acute viral respiratory infections J Fam Pract 2000; 49: 401-406

2 Allen LV. Colds \& cough. Int J Pharm Compd 2012; 16: 480-483

3 Singh $M$, Singh $M$. Heated, humidified air for the common cold. Cochrane Database Syst Rev 2013; 6: CD001728

4 Wenzel RP, Fowler AA 3rd. Clinical practice. Acute bronchitis. N Engl J Med 2006; 355: 2125-2130

5 Gulliford MC, van Staa T, McDermott $L$ et al. Cluster randomised trial in the General Practice Research Database: 1. Electronic decision support to reduce antibiotic prescribing in primary care (eCRT study). Trials 2011; $12: 115$

6 Butler CC, Hood $K$, Verheij T et al. Variation in antibiotic prescribing and its impact on recovery in patients with acute cough in primary care: prospective study in 13 countries. BMJ 2009; 338: b2242

7 Llor C, Moragas A, Bayona C et al. Efficacy of anti-inflammatory or antibiotic treatment in patients with non-complicated acute bronchitis and discoloured sputum: randomised placebo controlled trial. BMJ 2013; 347: f5762

8 Smith SM, Fahey T, Smucny J et al. Antibiotics for acute bronchitis. Cochrane Database Syst Rev 2014; 3: CD000245

\footnotetext{
${ }^{2}$ The authors would like to thank Dr. F. Erdnüß, Wiesbaden, for providing medical writing and Dr. Willmar Schwabe GmbH\&CoKG, Karlsruhe, Germany, for the support of this study on validity of BSS. The company put all original trial data used in this article at the authors disposal and supported the analyses financially.
} 
9 Lemiengre MB, van Driel ML, Merenstein D et al. Antibiotics for clinically diagnosed acute rhinosinusitis in adults. Cochrane Database Syst Rev 2012; 10: CD006089

10 McCallum GB, Morris PS, Chang AB. Antibiotics for persistent cough or wheeze following acute bronchiolitis in children. Cochrane Database Syst Rev 2012; 12: CD009834

11 Birring SS, Fleming T, Matos $S$ et al. The Leicester Cough Monitor: preliminary validation of an automated cough detection system in chronic cough. Eur Respir J 2008; 31: 1013 - 1018

12 Matos S, Birring SS, Pavord ID et al. An automated system for 24-h monitoring of cough frequency: the leicester cough monitor. IEEE Trans Biomed Eng 2007; 54: 1472-1479

13 Lee KK, Matos S, Evans DH et al. A longitudinal assessment of acute cough. Am J Respir Crit Care Med 2013; 187: 991 - 997

14 Thompson M, Vodicka TA, Blair PS et al. Duration of symptoms of respiratory tract infections in children: systematic review. BMJ 2013; 347: f7027

15 Hobbs KF, Cohen MD. Rheumatoid arthritis disease measurement: a new old idea. Rheumatology (Oxford) 2012; 51 (Suppl. 06): vi21 - 27

16 Hamilton M. A rating scale for depression. J Neurol Neurosurg Psychiatry 1960; 23: 56-62

17 Montgomery SA, Asberg M. A new depression scale designed to be sensitive to change. Br J Psychiatry 1979; 134: 382 - 389

18 Guskiewicz KM, Register-Mihalik J, McCrory P et al. Evidence-based approach to revising the SCAT2: introducing the SCAT3. Br J Sports Med 2013; 47: 289-293

19 Albrecht H, Vernon M, Solomon G. Patient-reported outcomes to assess the efficacy of extended-release guaifenesin for the treatment of acute respiratory tract infection symptoms. Respir Res 2012; 13: 118

20 Mwachari C, Nduba V, Nguti R et al. Validation of a new clinical scoring system for acute bronchitis. Int J Tuberc Lung Dis 2007; 11: 12531259

21 Nduba VN, Mwachari CW, Magaret AS et al. Placebo found equivalent to amoxicillin for treatment of acute bronchitis in Nairobi, Kenya: a triple blind, randomised, equivalence trial. Thorax 2008; 63: 999-1005

22 Dome L, Schuster R. Umckaloabo - eine phytotherapeutische Alternative bei akuter Bronchitis im Kindesalter? Ärztezeitschrift für Naturheilverfahren 1996; 37: 216-222

23 Holmes WF, Macfarlane JT, Macfarlane RM et al. Symptoms, signs, and prescribing for acute lower respiratory tract illness. Br J Gen Pract 2001; 51: 177-181

24 Kamin W, Ilyenko LI, Malek FA et al. Treatment of acute bronchitis with EPs 7630: randomized, controlled trial in children and adolescents. Pediatr Int 2012; 54: 219-226

25 Kamin W, Maydannik V, Malek FA et al. Efficacy and tolerability of EPs 7630 in children and adolescents with acute bronchitis - a randomized, double-blind, placebo-controlled multicenter trial with a herbal drug preparation from Pelargonium sidoides roots. Int J Clin Pharmacol Ther 2010; 48: 184-191

26 Kamin W, Maydannik VG, Malek FA et al. Efficacy and tolerability of EPs 7630 in patients (aged 6-18 years old) with acute bronchitis. Acta Paediatr 2010; 99: 537-543

27 Matthys H, Funk P. EPs 7630 improves acute bronchitic symptoms and shortens time to remission. Results of a randomised, double-blind, placebo-controlled, multicentre trial. Planta Med 2008; 74: 686-692

28 Matthys $H$, Heger M. Treatment of acute bronchitis with a liquid herbal drug preparation from Pelargonium sidoides (EPs 7630): a randomised, double-blind, placebo-controlled, multicentre study. Curr Med Res Opin 2007; 23: 323-331

29 Matthys H, Heger M. EPs 7630-solution-an effective therapeutic option in acute and exacerbating bronchitis. Phytomedicine 2007; 14 (Suppl. 06): $65-68$

30 Matthys H, Kamin W, Funk $P$ et al. Pelargonium sidoides preparation (EPs 7630) in the treatment of acute bronchitis in adults and children. Phytomedicine 2007; 14 (Suppl. 06): 69-73
31 Matthys H, Lizogub VG, Malek FA et al. Efficacy and tolerability of EPs 7630 tablets in patients with acute bronchitis: a randomised, doubleblind, placebo-controlled dose-finding study with a herbal drug preparation from Pelargonium sidoides. Curr Med Res Opin 2010; 26: $1413-1422$

32 Matthys $H$, Eisebitt $R$, Seith $B$ et al. Efficacy and safety of an extract of Pelargonium sidoides (EPs 7630) in adults with acute bronchitis. A randomised, double-blind, placebo-controlled trial. Phytomedicine 2003; 10 (Suppl. 04): 7-17

33 Chuchalin AG, Berman B, Lehmacher W. Treatment of acute bronchitis in adults with a pelargonium sidoides preparation (EPs 7630): a randomized, double-blind, placebo-controlled trial. Explore (NY) 2005; 1: $437-445$

34 Haidvogl M, Heger M. Treatment effect and safety of EPs 7630-solution in acute bronchitis in childhood: report of a multicentre observational study. Phytomedicine 2007; 14 (Suppl. 06): 60-64

35 Cwientzek $U$, Ottillinger $B$, Arenberger $P$. Acute bronchitis therapy with ivy leaves extracts in a two-arm study. A double-blind, randomised study vs. an other ivy leaves extract. Phytomedicine 2011; 18: 1105 1109

36 Gruenwald J, Graubaum HJ, Busch R. Efficacy and tolerability of a fixed combination of thyme and primrose root in patients with acute bronchitis. A double-blind, randomized, placebo-controlled clinical trial. Arzneimittelforschung 2005; 55: 669-676

37 Gruenwald J, Graubaum HJ, Busch R. Evaluation of the non-inferiority of a fixed combination of thyme fluid- and primrose root extract in comparison to a fixed combination of thyme fluid extract and primrose root tincture in patients with acute bronchitis. A single-blind, randomized, bi-centric clinical trial. Arzneimittelforschung 2006; 56: $574-581$

38 Kemmerich B. Evaluation of efficacy and tolerability of a fixed combination of dry extracts of thyme herb and primrose root in adults suffering from acute bronchitis with productive cough. A prospective, doubleblind, placebo-controlled multicentre clinical trial. Arzneimittelforschung 2007; 57: 607-615

39 Gillissen A, Wittig T, Ehmen $M$ et al. A multi-centre, randomised, double-blind, placebo-controlled clinical trial on the efficacy and tolerability of GeloMyrtol(R) forte in acute bronchitis. Drug Res (Stuttg) 2013; 63: $19-27$

40 Kemmerich B, Eberhardt R, Stammer H. Efficacy and tolerability of a fluid extract combination of thyme herb and ivy leaves and matched placebo in adults suffering from acute bronchitis with productive cough. A prospective, double-blind, placebo-controlled clinical trial. Arzneimittelforschung 2006; 56: $652-660$

41 Marzian 0 . Treatment of acute bronchitis in children and adolescents. Non-interventional postmarketing surveillance study confirms the benefit and safety of a syrup made of extracts from thyme and ivy leaves [Article in German]. MMW Fortschritte der Medizin 2007; 149 (Suppl. 27): 69-74

42 Steinsbekk A, Biolchini J, Heger M et al. Data Collection in Homeopathic Practice - A Proposal for an International Standard. 1999: 1 - 24. Available at: http://wwwhomeopathyeuropeorg/publications/guidelines/ data-collection/datacollhompracpdf [last accessed 03-02-2014]

43 Lehrl S. Report on the validity of the Bronchitis Severity Scale (BSS) - a scale for acute bronchitis. Internal Report for Dr Willmar Schwabe GmbH \& Co KG Karlsruhe: 2012: 1-78

44 Moosbrugger H, Kelava A. Testtheorie und Fragebogenkonstruktion. 2. ed. Berlin: Springer; 2007

45 European Medicines Agency. Committee on Herbal Medicinal Products (HMPC) meeting report on Community herbal monographs, guidelines and other activities. EMA/HMPC/301544/2013

46 Matthys H, Kamin W. Positioning of the Bronchitis Severity Score (BSS) for standardised use in clinical studies. Current medical research and opinion 2013; 29: $1383-1390$ 